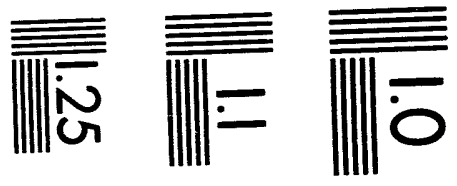

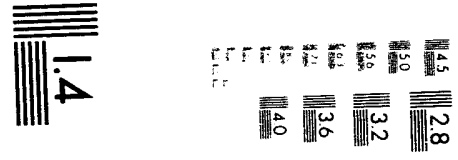

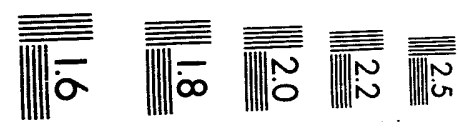



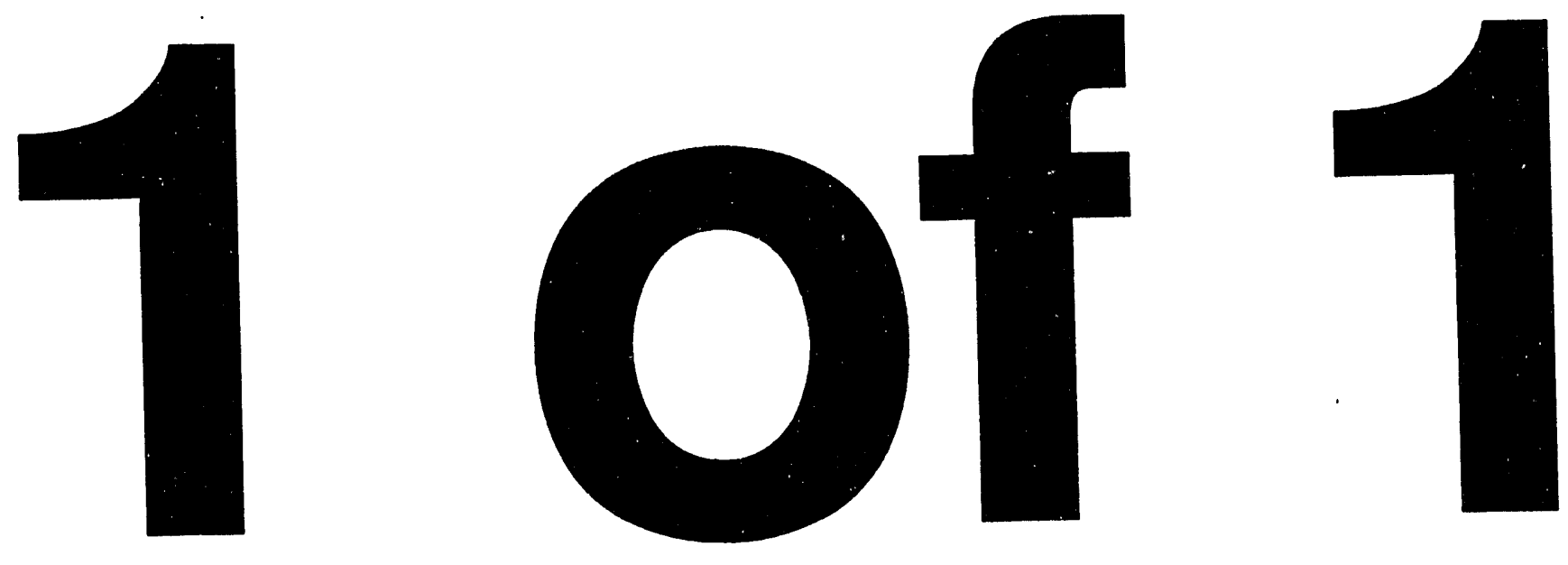
WSRC-TR-93-232

July 1993

\section{Atmospheric Pressure Fluctuations and Oxygen Enrichment in Waste Tanks(U)}

R. J. Kurzeja

Allen H. Weber

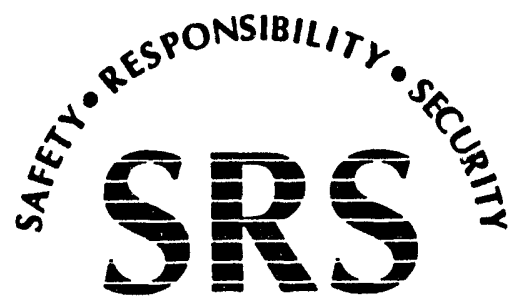

SAVANNAH RIVER SITE

Westinghouse Savannah River Company

Savannah River Technology Center

Alken, SC 29808 


\section{Atmospheric Pressure Fluctuations and Oxygen Enrichment in Waste Tanks}

\section{Executive Summary}

Oxygen enrichment in waste tanks can reach hazardous levels if normal purging is interrupted by power failures. In such cases it is necessary to estimate the time it would take for oxygen buildup to reach a critical concentration.

Mixing of outside air into closed tanks through small leaks will be slow without external forcing. One such extemal forcing mechanism is natural atmospheric pressure fluctuations, which can force air into tanks through small cracks or vent holes. The efficiency of this process is a function of the atmospheric pressure increases over time periods comparable to the in-tank mixing rate.

Two in-tank mixing rates were assumed ( 8 and 24 hours) and pressure measurements from Bush Field and SRTC's Climatology Site were analyzed to determine the mean and maximum pressure increases in a 5-year period 1986-1990.

The mean pressure increase in an 8-hr period was found to be $1.7 \mathrm{mb}$ and $5.0 \mathrm{mb}$ for a $24-\mathrm{hr}$ period. These pressure increases would induce an air enrichment of $-0.2 \%$ and $-0.5 \%$ for 8 and 24 -hour periods, respectively. Since oxygen is $21 \%$ of air by volume the in-tank oxygen enrichment would be $\sim 1 / 5$ of the percentages listed above.

The above values over-estimate the enrichment rate because they do not include the reduction in efficiency as the in-tank oxygen level increases and because they assume complete mixing of oxygen entering the tank.

\section{Introduction}

During In-Tank Precipitation (ITP) processing radiolytic decomposition of tetraphenylborate and water can produce benzene and hydrogen, which, given sufficiently high oxygen concentrations, can deflagrate. To prevent accumulations of benzene and hydrogen and avoid deflagration, continuous nitrogen purging is maintained

If the nitrogen purging is interrupted by, for example, a power failure, outside air will begin to seep into the tank through vent holes and cracks. Eventually a flammable mixture of benzene, hydrogen, and oxygen will occur (deflagration). However, this process is slow under steady-state conditions (constant pressure) and mechanisms to increase the exchange rate with the outside atmosphere must be considered.

The most important mechanism of this kind is from natural atmospheric pressure fluctuations in which an increase in atmospheric pressure forces air into the tank which then mixes with the hydrogenbenzene mixture. The subsequent decrease in atmospheric pressure causes venting from the tank of the mixture - the net effect being an increase in the tank's oxygen concentration. Thus, enrichment occurs when the atmospheric pressure increases but not when the pressure decreases. Moreover, this natural atmospheric "pumiping" is only important if the pressure fluctuations take place on a time scale longer than the characteristic mixing time scale (CMT) of the tank. If pressure lluctuations have a significantly higher frequency than the CMT, outside air will be forced in o iste tank and then out again before any significsin mixing can socur. The CMT is not known for cp tain, but is arimated to be between 8 and " $A \mathrm{~A}$ how .

The purpose of shs 3 fort is t analyze yearly pressure fluct wions fos a five year period to determine thew statistcsil phopenies over 8 and 24 hour periods. The analysis alsu includes a special breakdown into suryiner aid winter seasons and an analysis of $15 \times$ minute data from the SRTC Climatology firias. 


\section{Summary of Tasks}

The project involves three tasks:

(1) A statistical analysis of a 5-yr (1986-90) data base of one hour data from Bush Field in Augusta, Ga.

(2) Creation of a quality-assured, continuous, 2 month (Dec 92-Jan 93) data base of 15-minute data.

(3) A statistical analysis like that of task (1) but for the 2-month data base created in Task (2)

\section{Task 1}

This task used 5 years of pressure data (1986-1990) from Bush Field in Augusta. The data were obtained by National Weather Service personnel every hour from an aneroid barometer, which is compared once per week with a mercury barometer. The precision is 0.01 inches of mercury. The data were obtained from the Southeast Regional Climate Center in Columbia, SC. The Environmental Technology Section cannot verify the accuracy of this data independently. However, it has been subject to National Weather Service QA checks.

The statistical variable of interest is the sum of the pressure increases during a given period. This variable can be positive even if the pressure trend is downward during the period because only pressure increases are included. It is defined as the total pressure increase, TPI,

$$
\mathrm{TPI}=\sum_{\mathrm{i}=1}^{\mathrm{i}=8,24} \Delta \mathrm{P}_{\mathrm{i}}(+)
$$

where, $\Delta \mathrm{P}_{\mathrm{i}}(+)=$ a positive pressure change and the sum is over 8 or 24 hours.

The mean TPI (MTPI) is defined as,

$$
\mathrm{MTPI}=\frac{1}{1095,365} \sum_{\mathrm{i}=1}^{\mathrm{i}=1095,365} \operatorname{TPI}_{\mathrm{i}}
$$

where, 1095 and 365 are the number of 8 and $24-\mathrm{hr}$ periods in a year.

Additional quantities were also determined, including the standard deviation, the maximum, and the minimum of the TPI.

The statistical analysis was carried out with the SAS program listed in Appendix 1. The output from this program is shown in Tables 1 and 2 . In these tables the line PR_SM_8 (or_24) refers to the pressure data while the line CNT_8 (or_24) refers to the number of 1 -hr pressure increases in 8 or 24 hours. The variables are,

$\mathrm{N}=$ number of 8 or 24 hour periods

First line (PR_SM_8,PR_SM_24)

Mean $=$ MTPI, mb

Std Dev = standard deviation about the MTPI, mb

Minimum $=$ minimum TPI for the year, mi

Maximum $=$ maximum TPI for the year, $\mathrm{mb}$

Second line (CNT_8,CNT_24):

Mean $=$ mean number of pressure increases in an 8 or 12-hour period.

Std Dev = standard deviation of the number of pressure increases.

Minimum $=$ minimum number of pressure increases during any period.

Maximum $=$ maximum number of pressure increases in any 8 or 24 hr period.

From Table 1 the mean pressure increases for the entire 5 year period can be found. In an 8-hr period the mean increase is $1.7 \mathrm{mb}$ while for a 24-hr period it is $5.0 \mathrm{mb}$. The maximum pressure increases for any 8 $\mathrm{hr}$ period or 24-hr period were $11.3 \mathrm{mb}$ and $20.1 \mathrm{mb}$, respectively.

One feature of the tables require further explanation. The average number of pressure increases in 8 and 24 hours is expected to be 4 and 12 respectively but this was not the case. For example, in 1986 (Table 1) the mean number of pressure increases in an 8-hour period was 3.09. This difference is due to the finite resolution of the pressure data $(0.01$ inches of mercury) which causes changes in pressure of less than 0.01 inch to be classified as neither an increase nor a decrease.

It is of practical interest to know whether the danger of deflagration is greater in one season than another. Seasonal dependence is expected since the greatest pressure fluctuations are caused by synoptic weather systems, which are relatively infrequent in summer. The statistics for winter and summer (JanuaryFebruary-December and June-July-August) were calculated separately for the 5 years and are shown in Table 2. As expected, larger pressure increases are seen in the winter than in the summer for both 8-hr and $24-\mathrm{hr}$ periods. For an 8 -hr period the winter mean 
is $1.8 \mathrm{mb}$ and the summer mean is $1.5 \mathrm{mb}$. For $24-\mathrm{hr}$ period the winter mean is $5.5 \mathrm{mb}$ and the summer mean is $4.6 \mathrm{mb}$.

\section{Task 2}

In this task a two-month data set of 15-minute averaged data was created from atmospheric pressure data collected at Environmental Technology's Climatology Site. This data is collected every $1.5 \mathrm{sec}$ and anchived on ET's VAX computers. The sensor is a Rosemont capacitance device S/N 20135 (MTE \# L0046943) and is described in Table 3.

Quality assurance for this sensor is accomplished through twice-yearly calibration by ET personnel, periodic comparison to a mercury standard, and continuous comparison with Bush Field data. The sensor was calibrated by ET personnel on Nov 11 , 1992.

A copy of the calibration sheet is shown in Appendix 2. The sensor was found to have a $+1.02 \mathrm{mb}$ bias with respect to Rosemont S/N 20136 and a $-1.76 \mathrm{mb}$ bias compared to elevation-adjusted Bush Field data. Since these differences are greater than the specifications for this sensor (Table 3) and the sensor was installed only one month previously, additional calibrations were initiated.

In December a mercury barometer Princo TE-586, S/N 0864 was calibrated by the SRTC Standards Lab, Appendix 3. This barometer was compared to the Rosemont S/N 20135 on December 18-22 of 1992. In this comparison, the Rosemont was found to have a bias of $-0.7 \mathrm{mb}$.

The Rosemont was compared to Bush Field data (corrected for elevation differences). A plot of this comparison is shown in Fig. 1. This Figure shows good correlation between the sensors, with a $1-2 \mathrm{mb}$ negative bias of Rosemont 20135 with respect to the Bush Field data. Part of this difference is due to uncertainty about the precise elevation of the Climatology Site.
From these tests we draw the following conclusions. Since the Rosemont sensors S/N 20135 and 20136 differ by more than the specified accuracy $(0.3 \mathrm{mb})$, the vendor's factory calibration is rejected and the November 11 calibration is therefore not complete. Instead, the December calibration with the mercury barometer is accepted. Furthermore, since S/N 20135 was found to correlate well with Bush Field data, we accept the vendor's specification for repeatability $(0.03 \mathrm{mb})$. Thus, the December and January data are assumed to have a $-0.7 \mathrm{mb}$ absolute bias and to satisfy the manufacturer's specified precision. No instrument drift was seen during the period.

During December and January 24 hours of pressure data $(1.8 \%)$ were missing due to VAX downtimes. These data were replaced (filled-in) by linear interpolation or (for periods longer than 2 hours) by interpolation based on microbarograph data located in Building 773-A. The interpolated periods have the correct trends but lack some of the high frequency structure present in the complete data. The beginning time and date of the longer data gaps are listed below.

$\begin{array}{rrr}11 \text { Dec } 1992 & 21: 30 \text { GMT } & 16 \text { periods } \\ 8 \text { Jan } 1993 & 21: 15 \text { GMT } & 15 \text { periods } \\ \text { 19 Jan 1993 } & 16: 45 \text { GMT } & 38 \text { periods } \\ \text { 21 Jan 1993 } & 16: 45 \text { GMT } & 8 \text { periods }\end{array}$

Plots of all the data are shown in Figs. 2-9. As can seen be from the Figures, the filled periods cannot be easily distinguished from the other data.

\section{Task 3}

This task repeated the analysis of Task 1 , but with the Climatology data created in Task 2 . The results are shown in Table 4 . The line labeled CNT_8 contains entries roughly 4 times the entries in Table 1 because there are 4 times as many periods per 8 or 24-hour period. The results are otherwise consistent with the results of Table 1 if the difference in data series length is considered.

\section{Discussion}

The results of this study can be applied to waste tanks which are internally well mixed but which exchange gas slowly with the outside atmosphere. Under these conditions the slow steady-state diffusive exchange will be greatly accelerated by natural atmospheric "pumping" from pressure fluctuations.
An approximate indication of the efficiency of this process can be inferred from the average pressure increases. The average total pressure increases were found to be $1.7 \mathrm{mb}$ and $5.0 \mathrm{mb}$ for 8 and $24-\mathrm{hr}$ periods respectively. For a mean pressure of $1000 \mathrm{mb}$ this corresponds to a dilution rate of $0.2 \%$ and $0.5 \%$ for the first 8 and 24 hour periods. 
On March 13, 1993 the lowest pressure ever recorded at Bush Field in Augusta was measured. This minimum was due to a major winter storm called the "storm of the century". The extreme pressure changes observed for this storm at SRS were $28 \mathrm{mb}$ in an 8-iti period and $51 \mathrm{mb}$ in a $24-\mathrm{hr}$ period. These values are over twice as large as the maximum values seen in the 5 year data base 1986-1990. Since they occurred with the lowest pressure ever recorded at Bush Field, they are a good estimate of the "100-year" pressure change.

A rigorous solution to the problem would require a differential equation for the oxygen concentration which includes the effects of inflow, outflow and internal mixing. A careful analysis would also consider the frequency dependence of the pressure fluctuations since time periods comparable to or larger than the CMT are most efficient.

The frequency dependence of the process is why conventional measures of variability, such as the standard deviation, are not suitable for this study. However, a variance spectrum of the pressure fluctuations would provide all the information necessary to solve this problem for any tank.

\section{Summary}

This study has determined the mean pressure increase for 8 and 12-hour periods for 5 years of Bush Field data. The mean 8-hr increase was $1.7 \mathrm{mb}$ and for 24 hours it was $5.0 \mathrm{mb}$. The maximum values seen in the 5 year period were $11.3 \mathrm{mb}$ for 8 hours and 20.2 $\mathrm{mb}$ for 24 hours.

The same quantities were obtained for summer and winter seasons. The mean winter values were larger $1.8 \mathrm{mb}$ and $5.5 \mathrm{mb}$ respectively, while the mean summer values were smaller $-1.5 \mathrm{mb}$ and $4.5 \mathrm{mb}$ respectively. This result was expected, considering the greater frequency of weather systems in the winter.

The analysis was repeated using data collected from SRTC's Climatology Site for January and December of 1992-1993. The mean increases in pressure were found to be $2.4 \mathrm{mb}$ and $7.1 \mathrm{mb}$. 
Table 1. Output from SAS program for 1986-90. The lines labeled PR_SM_8 and PR_SM_24 are in mb, except for N. The lines labeled CNT_8 and CNT_24 are in number of periods.

1986 Data

\begin{tabular}{|l|c|c|c|c|c|}
\hline Variable & $\mathrm{N}$ & Mean & Std Dev & Minimum & Maximum \\
\hline PR_SM_8 & 1095 & 1.6814568 & 1.3290675 & 0 & 8.4660439 \\
\hline CNT_8 & 1095 & 3.0940639 & 1.8684603 & 0 & 8.0000000 \\
\hline
\end{tabular}

1986 Data

\begin{tabular}{|l|c|c|c|c|c|}
\hline Variable & N & Mean & Std Dev & Minimum & Maximum \\
\hline PR_SM 24 & 365 & 5.0443705 & 2.6964310 & 0 & 15.9161626 \\
\hline CNT 24 & 365 & 9.2821918 & 3.6419165 & 0 & 20.0000000 \\
\hline
\end{tabular}

1987 Data

\begin{tabular}{|l|c|c|c|c|c|}
\hline Variable & $\mathrm{N}$ & Mean & Std Dev & Minimum & Maximum \\
\hline PR_SM 8 & 1095 & 1.6819207 & 1.3642457 & 0 & 9.3126483 \\
\hline CNT 8 & 1095 & 3.1442922 & 1.9153001 & 0 & 8.0000000 \\
\hline
\end{tabular}

1987 Data

\begin{tabular}{|l|c|c|c|c|c|}
\hline Variable & N & Mean & Std Dev & Minimum & Maximum \\
\hline PR SM 24 & 365 & 5.0457622 & 2.9433449 & 0 & 19.8105428 \\
\hline CNT 24 & 365 & 9.4328767 & 3.7282724 & 0 & 24.0000000 \\
\hline
\end{tabular}

1988Data

\begin{tabular}{|l|c|c|c|c|c|}
\hline Variable & $\mathrm{N}$ & Mean & Std Dev & Minimum & Maximum \\
\hline PR_SM 8 & 1098 & 1.6716196 & 1.3763875 & 0 & 10.4978945 \\
\hline CNT 8 & 1098 & 3.1293260 & 1.8679360 & 0 & 8.0000000 \\
\hline
\end{tabular}

1988Data
\begin{tabular}{|l|c|c|c|c|c|}
\hline Variable & N & Mean & Std Dev & Minimum & Maximum \\
\hline PR_SM_24 & 366 & 5.0148588 & 2.6615211 & 0 & 14.9002373 \\
\hline CNT 24 & 366 & 9.3879781 & 3.4912443 & 0 & 20.0000000 \\
\hline
\end{tabular}

1989Data
\begin{tabular}{|l|c|c|c|c|c|}
\hline Variable & N & Mean & Std Dev & Minimum & Maximum \\
\hline PR_SM_8 & 1095 & 1.6424898 & 1.3018849 & 0 & 11.3444988 \\
\hline CNT_8 & 1095 & 3.2000000 & 1.8328707 & 0 & 8.0000000 \\
\hline
\end{tabular}

1989Data
\begin{tabular}{|l|c|c|c|c|c|}
\hline Variable & N & Mean & Std Dev & Minimum & Maximum \\
\hline PR_SM_24 & 365 & 4.9274695 & 2.7143222 & 0 & 19.6412219 \\
\hline CNT_24 & 365 & 9.6000000 & 3.5025893 & 0 & 22.0000000 \\
\hline
\end{tabular}

1990Data
\begin{tabular}{|l|c|c|c|c|c|}
\hline Variable & N & Mean & Std Dev & Minimum & Maximum \\
\hline PR_SM 8 & 1095 & 1.7216609 & 1.4194222 & 0 & 10.1592527 \\
\hline CNT 8 & 1095 & 3.3744292 & 1.9251259 & 0 & 8.0000000 \\
\hline
\end{tabular}

1990Data
\begin{tabular}{|l|c|c|c|c|c|}
\hline Variable & N & Mean & Std Dev & Minimum & Maximum \\
\hline PR SM 24 & 365 & 5.1649826 & 2.9609116 & 0 & 20.1491845 \\
\hline CNT 24 & 365 & 10.1232877 & 3.7326345 & 0 & 20.0000000 \\
\hline
\end{tabular}


Table 2. Output from SAS program for summer and winter of 1986-1990. The first two sections are for summer (June, July and August). The second two sections are for wnter (January, February, and March). The lines labeled PR_SM_8 and PR_SM_24 are in mb, except for N. The lines labeled CNT_8 and CNT-24 are in number of periods.

Summer

1986 Data

\begin{tabular}{|l|c|c|c|c|c|}
\hline Variable & $\mathrm{N}$ & Mean & Std Dev & Minimum & Maximum \\
\hline PR_SM_8 & 276 & 1.5858495 & 1.1250971 & 0 & 6.7728351 \\
\hline CNT_8 & 276 & 2.9601449 & 1.6006380 & 0 & 7.0000000 \\
\hline
\end{tabular}

1986 Data

\begin{tabular}{|l|l|l|l|l|r|}
\hline PR_SM_24 & 92 & 4.7575486 & 1.7405630 & 1.3545670 & 9.8206109 \\
\hline CNT_24 & 92 & 8.8804348 & 2.6179532 & 4.0000000 & 16.0000000 \\
\hline
\end{tabular}

Winter

1986 Data

\begin{tabular}{|l|c|c|c|c|c|}
\hline Variable & $\mathrm{N}$ & Mean & Std Dev & Minimum & Maximum \\
\hline PR_SM_8 & 270 & 1.9979864 & 1.6957624 & 0 & 8.4660439 \\
\hline CNT_8 & 270 & 3.3444444 & 2.1770744 & 0 & 8.0000000 \\
\hline
\end{tabular}

1986 Data

\begin{tabular}{|l|c|c|c|c|c|}
\hline PR_SM_24 & 90 & 5.9939591 & 3.6503556 & 0 & 15.9161626 \\
\hline CNT_24 & 90 & 10.0333333 & 4.6481844 & 0 & 18.0000000 \\
\hline
\end{tabular}

Summer

1987 Data

\begin{tabular}{|l|c|c|c|c|c|}
\hline Variable & N & Mean & Std Dev & Minimum & Maximum \\
\hline PR_SM_8 & 276 & 1.4232769 & 0.9030636 & 0 & 4.2330220 \\
\hline CNT_8 & 276 & 2.9239130 & 1.5717994 & 0 & 7.0000000 \\
\hline
\end{tabular}

1987 Data

\begin{tabular}{|l|c|c|c|c|c|}
\hline PR_SM_24 & 92 & 4.2698308 & 1.2848163 & 2.0318505 & 7.7887604 \\
\hline CNT 24 & 92 & 8.7717391 & 2.2193121 & 5.0000000 & 15.0000000 \\
\hline
\end{tabular}

Winter

1987 Data

\begin{tabular}{|l|c|c|c|c|c|}
\hline Variable & $\mathrm{N}$ & Mean & Std Dev & Minimum & Maximum \\
\hline PR_SM_8 & 270 & 2.0682232 & 1.7554968 & 0 & 9.3126483 \\
\hline CNT_8 & 270 & 3.3629630 & 2.1800290 & 0 & 8.0000000 \\
\hline
\end{tabular}

1987 Data

\begin{tabular}{|l|l|l|l|l|l|}
\hline PR_SM_24 & 90 & 6.2046695 & 4.0549173 & 0 & 19.8105428 \\
\hline CNT_24 & 90 & 10.0888889 & 4.7985120 & 0 & 24.0000000 \\
\hline
\end{tabular}


Table 2. (Continued)

Summer

1988 Data

\begin{tabular}{|l|c|c|c|c|c|}
\hline Variable & $\mathrm{N}$ & Mean & Std Dev & Minimum & Maximum \\
\hline PR SM 8 & 276 & 1.4846251 & 1.1728743 & 0 & 8.1274022 \\
\hline CNT 8 & 276 & 2.9927536 & 1.6203092 & 0 & 8.0000000 \\
\hline
\end{tabular}

1988 Data

\begin{tabular}{|l|l|l|l|l|l|}
\hline PR SM 24 & 92 & 4.4538753 & 1.9015732 & 0.6772835 & 11.6831406 \\
\hline CNT 24 & 92 & 8.9782609 & 2.8592563 & 2.0000000 & 16.00000000 \\
\hline
\end{tabular}

Winter

1988 Data

\begin{tabular}{|l|c|c|c|c|c|}
\hline Variable & $\mathrm{N}$ & Mean & Std Dev & Minimum & Maximum \\
\hline PR SM 8 & 273 & 1.9140082 & 1.6129903 & 0 & 10.4978945 \\
\hline CNT 8 & 273 & 3.2417582 & 2.0418813 & 0 & 8.0000000 \\
\hline
\end{tabular}

1988 Data

\begin{tabular}{|l|l|l|l|l|l|}
\hline PR SM 24 & 91 & 5.7420245 & 3.2257638 & 0 & 14.7309164 \\
\hline CNT 24 & 91 & 9.7252747 & 4.0001831 & 0 & 20.0000000 \\
\hline
\end{tabular}

Summer

1989 Data

\begin{tabular}{|l|c|c|c|c|c|}
\hline Variable & $\mathrm{N}$ & Mean & Std Dev & Minimum & Maximum \\
\hline PR SM 8 & 276 & 1.4404544 & 0.9300458 & 0 & 4.5716637 \\
\hline CNT 8 & 276 & 3.0833333 & 1.4784308 & 0 & 8.00000000 \\
\hline
\end{tabular}

1989 Data

\begin{tabular}{|l|c|c|c|c|c|}
\hline PR_SM 24 & 92 & 4.3213633 & 1.4798309 & 1.5238879 & 9.3126483 \\
\hline CNT_24 & 92 & 9.2500000 & 2.4161772 & 5.0000000 & 19.0000000 \\
\hline
\end{tabular}

Winter

1989 Data

\begin{tabular}{|l|c|c|c|c|c|}
\hline Variable & $\mathrm{N}$ & Mean & Std Dev & Minimum & Maximum \\
\hline PR SM 8 & 270 & 1.7803777 & 1.4111918 & 0 & 8.2967230 \\
\hline CNT 8 & 270 & 3.1185185 & 1.8814368 & 0 & 8.0000000 \\
\hline
\end{tabular}

1989Data

\begin{tabular}{|l|l|l|l|l|l|}
\hline PR_SM_24 & 90 & 5.3411330 & 2.8389776 & 1.0159253 & 12.8683868 \\
\hline CNT 24 & 90 & 9.3555556 & 3.6205131 & $3.000 \times 0000$ & $16.0000(00000$ \\
\hline
\end{tabular}


Table 2. (Continued)

Summer

1990 Data

\begin{tabular}{|l|c|c|c|c|c|}
\hline Variable & $\mathrm{N}$ & Mean & Std Dev & Minimum & Maximum \\
\hline PR SM 8 & 276 & 1.5692855 & 1.0367567 & 0 & 6.2648725 \\
\hline CNT 8 & 276 & 3.2355072 & 1.6444861 & 0 & 7.0000000 \\
\hline
\end{tabular}

1989 Data

PR SM 24

CNT 24

\begin{tabular}{|l|l|l|l|r|}
\hline 92 & 4.7078566 & 1.6075421 & 1.3545670 & 8.6353648 \\
\hline 92 & 9.7065217 & 2.5442806 & 4.0000000 & 15.0000000 \\
\hline
\end{tabular}

Winter

1990 Data

\begin{tabular}{|l|c|c|c|c|c|}
\hline Variable & $\mathrm{N}$ & Mean & Std Dev & Minimum & Maximum \\
\hline PR_SM_8 & 270 & 1.9177157 & 1.7379172 & 0 & 9.4819692 \\
\hline CNT_8 & 270 & 3.4444444 & 2.1302099 & 0 & 8.0000000 \\
\hline
\end{tabular}

1990Data

\begin{tabular}{|l|c|c|c|c|c|}
\hline PR_SM_24 & 90 & 5.7531472 & 3.9608529 & 0.6772835 & 20.1491845 \\
\hline CNT_24 & 90 & 10.3333333 & 4.5071728 & 2.0000000 & 21.00000000 \\
\hline
\end{tabular}


Table 3. Rosemont Pressure Sensor Data

Model

Serial Number

Purchase Date

Installation Date

Accuracy

Repeatability

Time constant

Calibration Dates
$1332 \mathrm{~A} 10$

20135, MTE 0046943

September, 1992

October, 1992

$0.3 \mathrm{mb}$

$0.03 \mathrm{mb}$

$0.01 \mathrm{sec}$

(1) Routine calibration Nov 11, 1992

(2) Calibration against mercury barometer TE-586. Instrument TE-586 was calibrated 12/3/92, traceable to NIST standard. 
Table 4. Output from SAS program for December and January of 1992-93. The lines labcled PR_SM_8 and PR_SM_24 are in mb, except for $N$. The lines labeled CNT_8 and CNT_24 are in number of periods.

1992-93 Data

1

14:52 Tuesday, February 16, 1993

\begin{tabular}{|l|c|c|c|c|c|}
\hline Variable & $\mathrm{N}$ & Mean & Std DeV & Minimum & Maximum \\
\hline PR_SM_8 & 186 & 2.3857527 & 1.4197304 & 0.1500000 & 6.5500000 \\
\hline CNT_8 & 186 & 16.1612903 & 6.5854718 & 3.0000000 & 30.0000000 \\
\hline
\end{tabular}

1992 Data

14:52 Tuesday, February 16, 1993

2

\begin{tabular}{|l|l|l|l|l|l|}
\hline PR_SM_24 & 62 & 7.1572581 & 2.4923293 & 0.7100000 & 11.4900000 \\
\hline CNT_24 & 62 & 48.4838710 & 12.9091935 & 10.0000000 & 72.0000000 \\
\hline
\end{tabular}


APPENDIX 1: SAS program for Tables 1 and 2.

The SAS Systen

18:36 Tuesday, February 9, 1993

NOTE: Copyright (c) 1989 by SAS Institute Inc. , Cary, NC USA.

NOTE: SAS (r) Proprietary Software Release 6.07 TS301

Licensed to WESTINGHOUSE SAVANNAH RIVER COMPANY, Site 0002398002.

NOTE: Ruming on VAX Model 8550 Serial Number $06840 E 15$.

Welcome to the new SAS System, Release 6.07.

ENVIRONMENTAL TECHNOLOGY SECTION

X 'SET DEFAULT SHADOW6: [SAS_WORK.PRESSURE]';

OPTIONS NOCENTER ERRORS $=2$;

FILENAME IN1 'DISK6: [KURZEJA] MORIN . DAT';

DATA NWS_92 CNT_8 CNT_24; INFILE IN1;

INPUT @2 FINETIM DATETIME15.@22 P_MB 7.2;

FORMAT FINETIM DATETIME13. P_MB 7.2;

TITLE FONT=SIMPLEX '1992-93 DATA';

RETAIN CNT 8;

KEEP FINETIM P_MB P_HR DIF WEEK

CNT 8 CNT 24 REM 8 REM 24 PR_SM_8PR_SM 24;

FORMAT FINETIM DATETIME10. PR_SM_8 6.2 PR_SM_24 6.2 CNT_84.CNT_24 4.;

IF MOD $(N, 672)=1$ THEN DO; WEEK + $;$ END;

P_HR_DIF=P_MB-LAG (P_MB);

REM_8=MOD $\left(N_{-}, 24\right)$;

REM_24=MOD $\left(\bar{N}_{-}, 96\right)$;

IF REM_8 $=1$ THEN DO; IF P_HR_DIF $>0.0$ THEN DO;

IF P_HR_DIF $<=0.0$ THEN DO;

END;

END;

CNT_8=1; PR_SM_8=P_HR_DIF ;

$$
\text { CNT_8=0; PR_SM_8=0.0; }
$$

IF REM_ $8^{\wedge}=1$ THEN DO; IF P_HR_DIF $>0.0$ THEN DO

CNT_8+1; PR_SM_8+P_HR_DIF;

IF REM_8 $=0$ THEN OUTPUT CNT_ 8 ;

END;

IF REM_24=1 THEN DO; IF P_HR_DIF>.0.0 THEN DO;

CNT_24=1; PR_SM_24=P_HR_DIF;

IF P HR DIF $<=0.0$ THEN DO

CNT_24=0; PR_SM_24=0.0;

END;

END;

IF REM_24^=1 THEN DO; IF P_HR-DIF $>0.0$ THEN DO;

CNT_24+1; PR_SM_24+P_HR-DIF;

END;

IF REM_24=0 THEN OUTPUT CNT_24;

OUTPUT NWS_92; 
Appendix 1 (Continued)

NOTE: The infile IN1 is:

File=\$1SDUS75: [KURZEJA] MORIN.DAT

NOTE: 6624 records were read from the infile IN1.

The minimum record length was 28.

The maximum record length was 31 .

NOTE: Missing values were generated as a result of performing an operation on missing values.

Each place is given by: (Number of times) at (Line): (Column).

1 at 23:14

NOTE; The data set WORK.NWS_92 HAS 6624 observations and 10 variables.

NOTE: The data set WORK.CNT_ 8 has 276 observations and 10 variables.

NOTE: The data set WORK.CNT_24 has 69 observations and 10 r riables.

DATA SUM_8; SET CNT_8;

KEEP FINETIM WEEK CNT_8 PR_SM_8;

NOTE; The data set WORK.SUM_8 has 276 observations and 4 variables.

DATA SUM_24; SET CNT_24;

KEEP FINETIM WEEK CNT_24 PR_SM_24;

NOTE: The data set WORK.SUM_24 has 69 observations and 4 variables. PROC MEANS DATA=SUM_8;

VAR PR_SM_8 CNT_8;

NOTE: The PROCEDURE MEANS printed page 1. PROC MEANS DATA=SUM_24;

VAR PR SM_24 CNT_24;

TITLE "1992 DATA";

ENDSAS;

NOTE: The PROCEDURE MEANS printed page 2.

The SAS System

18:36 Tuesday, February 9, 1993

NOTE: SAS Institute Inc., SAS Campus Drive Cary, NC USA 27513-2414 
Appendix 2. Calibration data for the Rosemont pressure sensor S/N 20135.

\section{BAROMETRIC PRESSURE ACCURACY \\ Procedure ETSP T105.2}

FORM OP.BP

Area: CCS Date: $11-17-92$ Operator: Helland/Hamilton

Equipment to be tested: Rosemont Pressure Transducer Model 1332

Procassor card: Teledyne Amplifier Medule 21.62

Field instrument Rosemont $\mathrm{S} / \mathrm{N}: 20135$ Calib. data 22.132 in $\mathrm{HG} O \mathrm{O} / 5$ volts Standard inst. Rosemont $S / N: \frac{20 / 36}{3130723}$ Callb. data 22.132. in $\mathrm{HG}$ e $/ 5$ volts Voltuneter

Fluke $S / N: 3130773$

Calibration begin time: $4: 18$ pim.

\begin{tabular}{|c|c|c|c|c|c|c|c|}
\hline \multicolumn{8}{|c|}{ 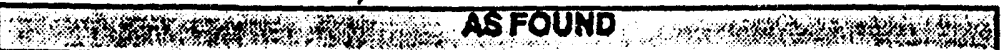 } \\
\hline का & $\begin{array}{l}\text { Fikte volus } \\
\text { (stenders) }\end{array}$ & 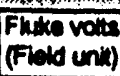 & $\begin{array}{l}\text { MAC vols } \\
\text { (Filold unit) }\end{array}$ & 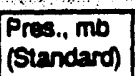 & $\begin{array}{l}\text { Press. mb } \\
\text { (Flold unia) }\end{array}$ & 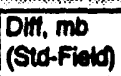 & $\begin{array}{l}\text { Dit. vols = } \\
\text { Muc-Expl) }\end{array}$ \\
\hline 1 & 3,915 & 3.931 & 3.937 & 1010.16 & 1011.25 & -1.09 & .006 \\
\hline 2 & 3.915 & 3.929 & 3.934 & 1010.16 & $1011 \mathrm{ll}$ & -.95 & .005 \\
\hline & $3.9 / 3$ & 3.928 & 3.934 & 101 & 1011.04 & -1.01 & .006 \\
\hline x & & & 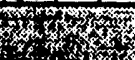 & & average. & -1.02 & 006 \\
\hline 20 & 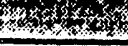 & & & & & $0.5 \mathrm{mb}$ & $0.005 y$ \\
\hline
\end{tabular}

\begin{tabular}{|c|c|c|c|c|c|c|c|}
\hline \\
\hline \multicolumn{8}{|c|}{ 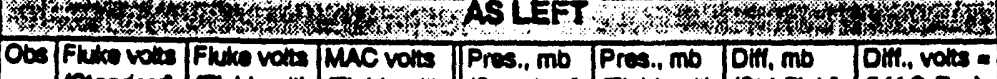 } \\
\hline$\pi$ & & & & & & & \\
\hline 2 & & & & & & & \\
\hline & & & & & & & \\
\hline & & & & & ave & & \\
\hline 8 & & & & & toler & \pm 0 & $0.005 y$ \\
\hline
\end{tabular}

Bush Field $(\mathrm{mb})=1023.60$ at time 5:00 1 Bush field (mb,corrected) $=1012.4$ Climatology $(\mathrm{mb})=1010.64$ at time $4: 50 \mathrm{pas}$.

\begin{tabular}{|c|c|c|c|c|c|c|c|c|c|c|}
\hline \multicolumn{11}{|c|}{ 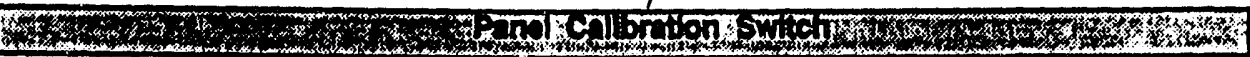 } \\
\hline & & Votion & Fluke & Ficke & Provious & Difienences & Expected & Emor & OK & taptem \\
\hline Astound & Fuck & $\begin{array}{l}\text { Fuke=.001 } \\
\text { MAC=.001 } \\
\text { MAC=.002 }\end{array}$ & $\checkmark$ & & $\operatorname{lat} x$ & la * & 0.0 & 001 & $\checkmark$ & \\
\hline Astound & मा & MAO- & & & rete & mele & 5.0 & 001 & 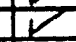 & \\
\hline Astont & LII & $\begin{array}{l}\text { MAC: } \\
\text { MACE }\end{array}$ & & & & & $\mid \frac{0.0}{50}$ & & & \\
\hline
\end{tabular}

Calibration end time: 5:05

comments: The ilimatoloyy eustodion has directed us to leave the old barometric pressure sensor installed until fie can determine which senser is oferating properly. Neither

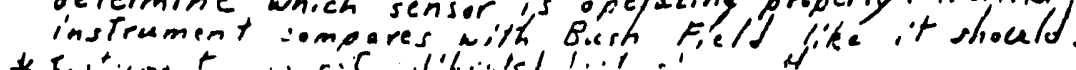


Appendix 3. Calibration data for the Princo mercury barometer.

SAVANNAH RIVER STANDARDS LABORATORY CALIBRATION CEKTIEICATE
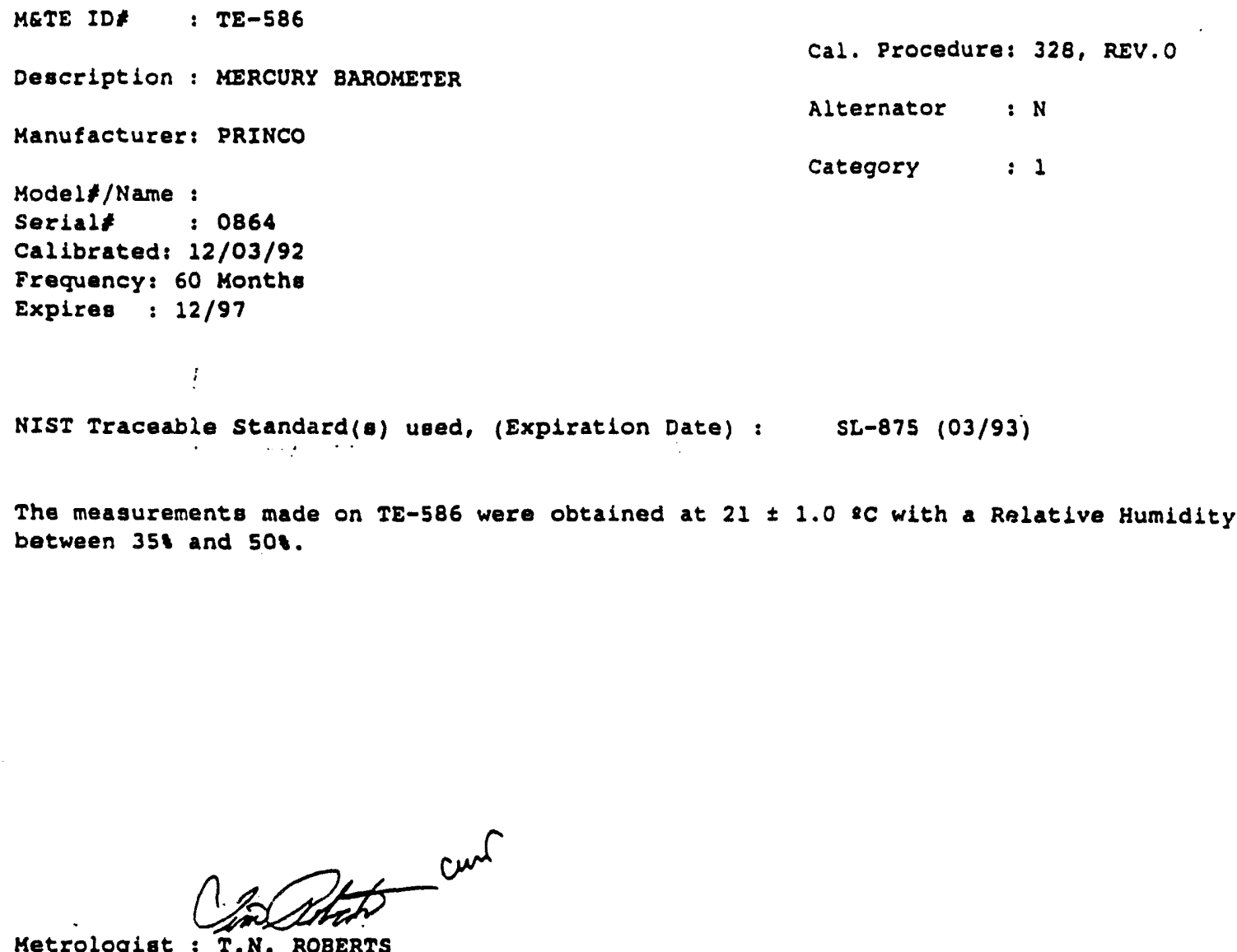

Metrologist : T.N. ROBERTS 
Appendix 3. Calibration Data for the Princo Mercury Barometer. (Continued)

Calibration Data for TE-586

\begin{tabular}{ccc}
$\begin{array}{c}\text { Applied Pressure } \\
\text { mBAR }\end{array}$ & $\begin{array}{c}\text { TE-586 Reading } \\
\text { mBAR }\end{array}$ & $\begin{array}{c}\text { TE-586 Corrected } \\
\text { mBAR }\end{array}$ \\
\hline 1000.265 & 1005.5 & 1000.901 \\
1000.265 & 1005.8 & 1001.199 \\
1000.265 & 1005.8 & 1001.199 \\
1000.198 & 1005.8 & 1001.199 \\
999.998 & 1005.6 & 1001.000 \\
1006.499 & 1011.75 & 1007.122 \\
1006.379 & 1011.7 & 1007.072 \\
1005.299 & 1010.8 & 1006.176 \\
1005.339 & 1010.8 & 1006.176 \\
1003.166 & 1008.6 & 1004.151 \\
1003.282 & 1008.5 & 1004.051
\end{tabular}

Note: The readings above were corrected for gravity and temperature using the equation supplied by the customer. The average difference of the corrected values above form the pressures applied must also be subtracted, which is $0.84 \mathrm{mBAR}$.

So, the final correction to any readings taken from TE-586 is:

$$
\text { Corrected pressure }=\left(\text { Reading }{ }^{*} \text { Local Gravity } / 980.665 *(1-0.000163 * \text { Temp. })\right)-0.84
$$

where local gravity is in $\mathrm{Cm} / \mathrm{S} / \mathrm{S}$ and temp. is in degrees Celsius.

The estimated uncertainty of the standard(s) and measurement process at SRSL is $\pm 0.02 \%$ RDG. 


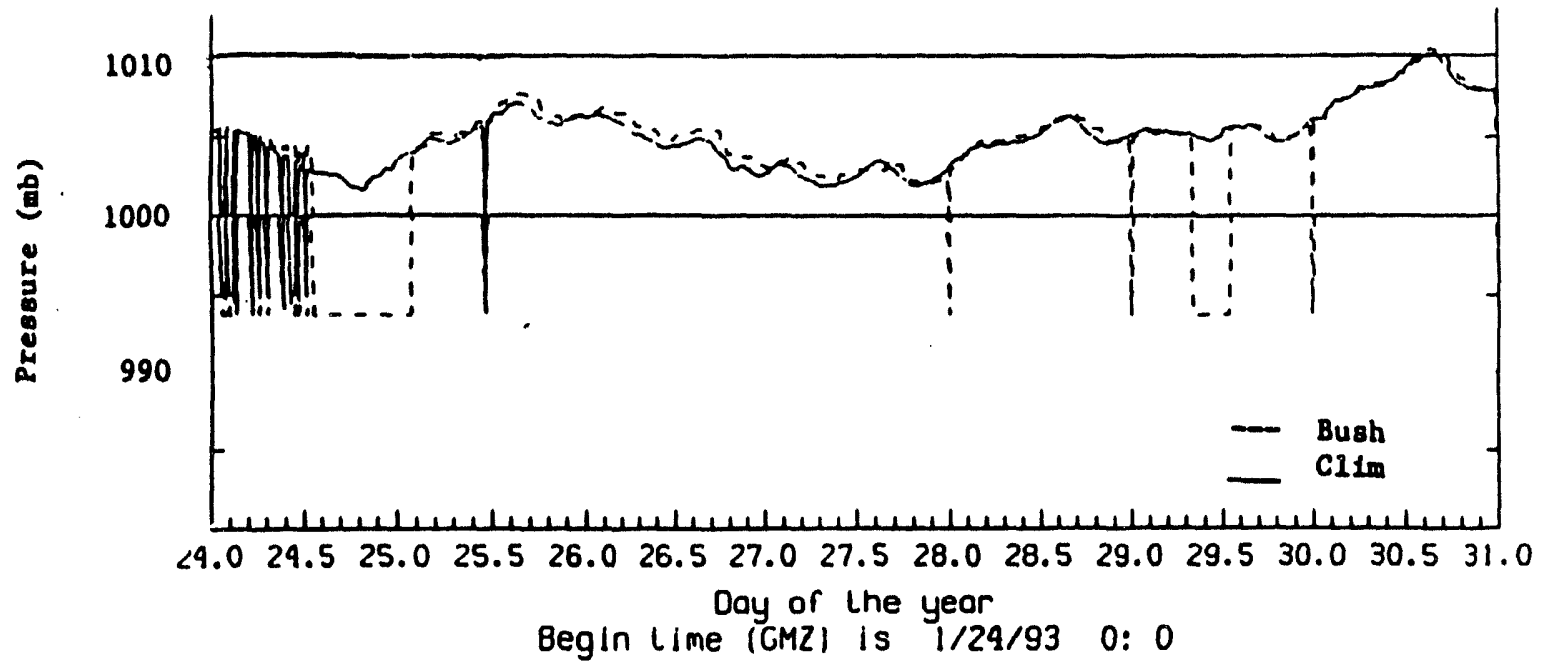

Figure 1. Plot of barometric sensor data at the Climatology Site in mb. The dashed line is Bush Field data. Vertical line segments show missing data. 


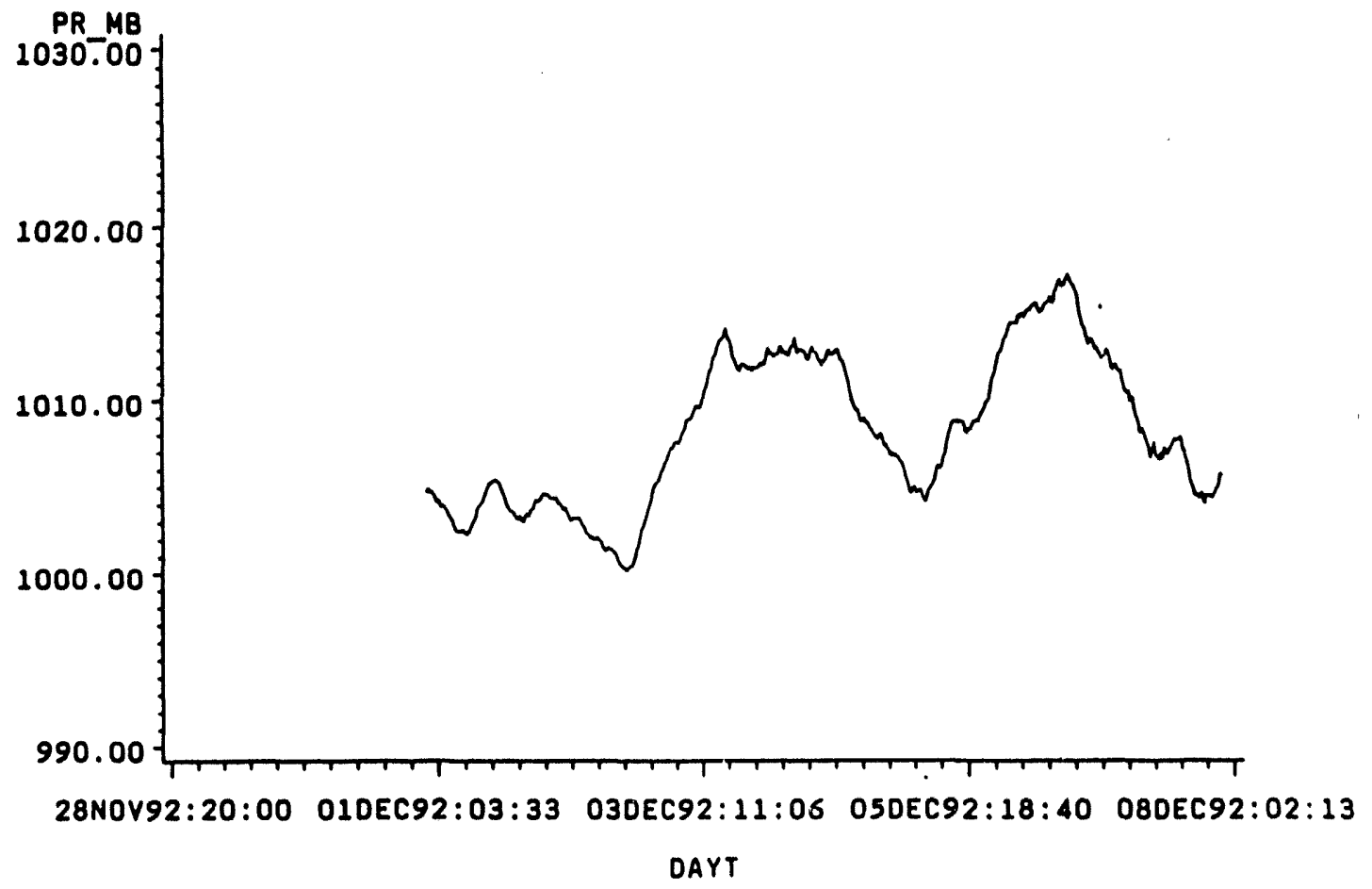

Figure 2. Climatology pressure data for week 1, December 1-8, 1992. 


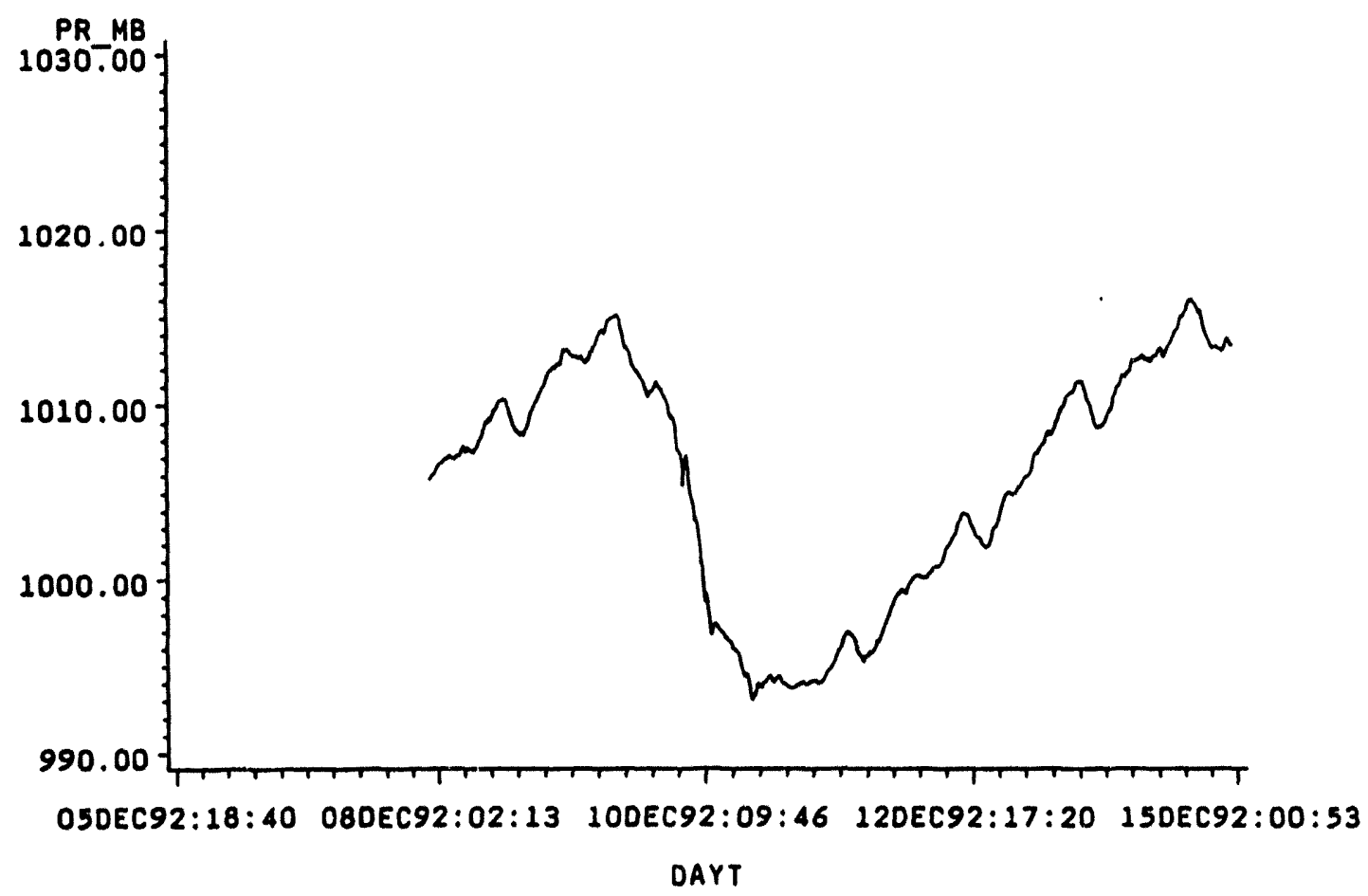

Figure 3. Climatology pressure data for week 2, December 8-15, 1992. 


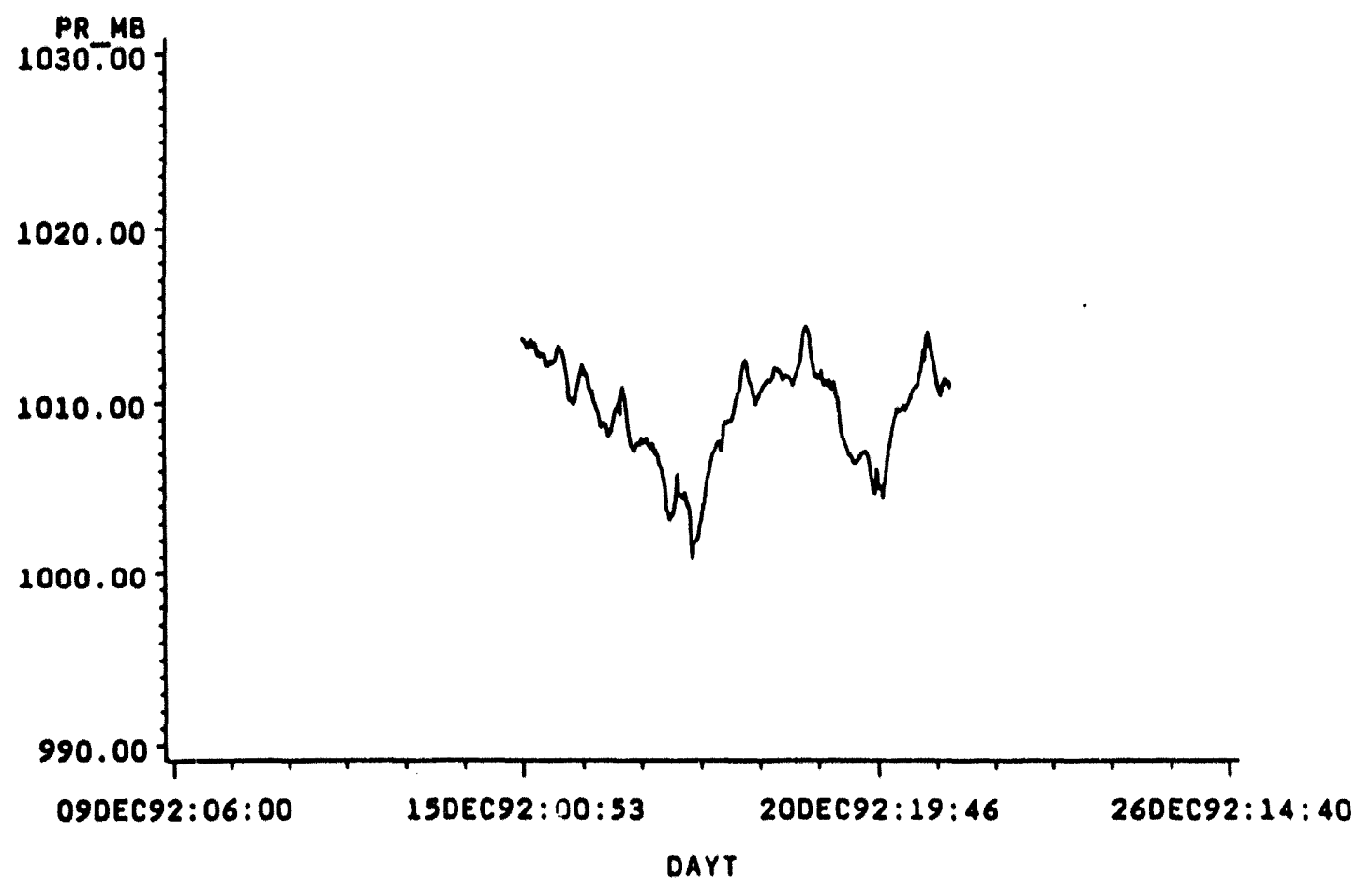

Figure 4. Climatology pressure data for week 3, December 15-21, 1992. 


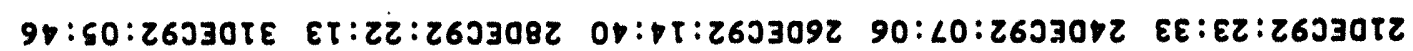

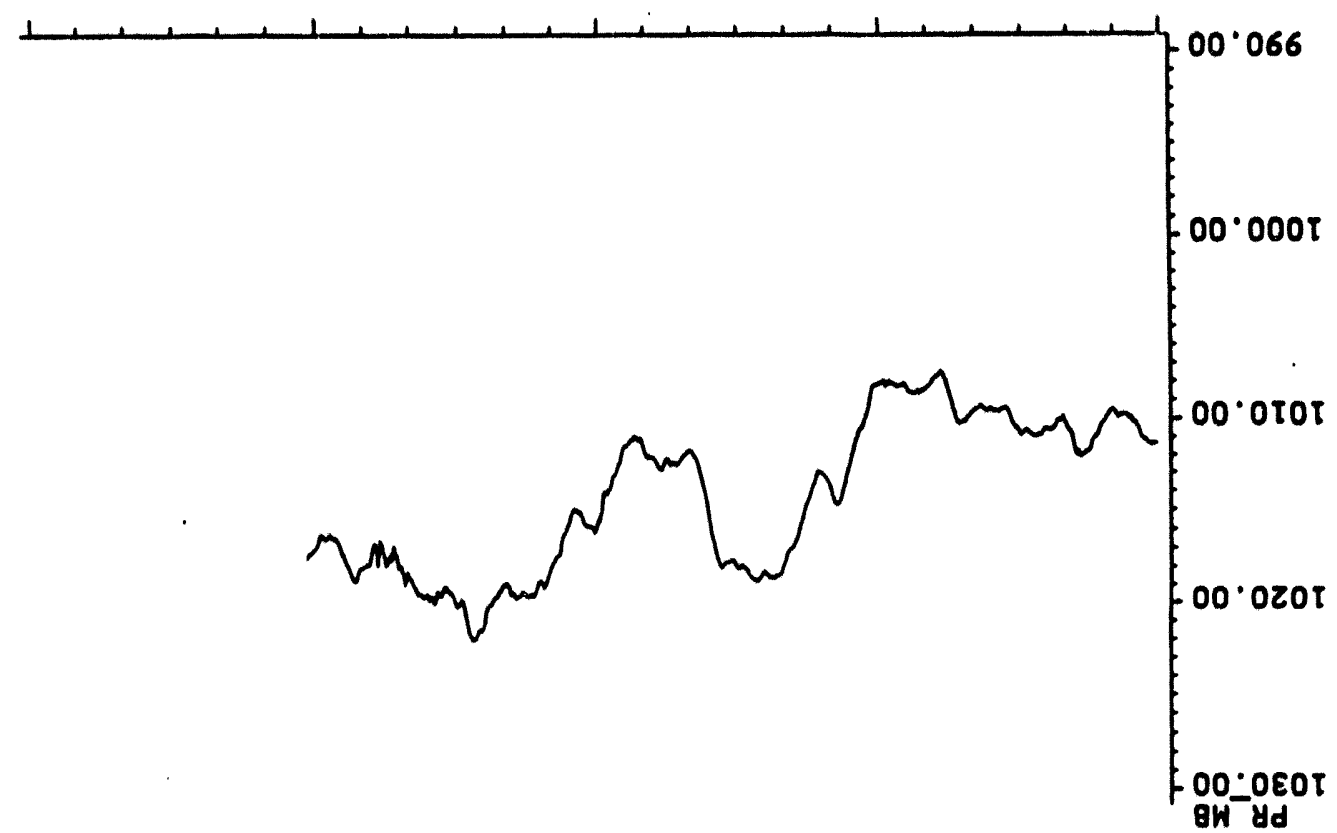




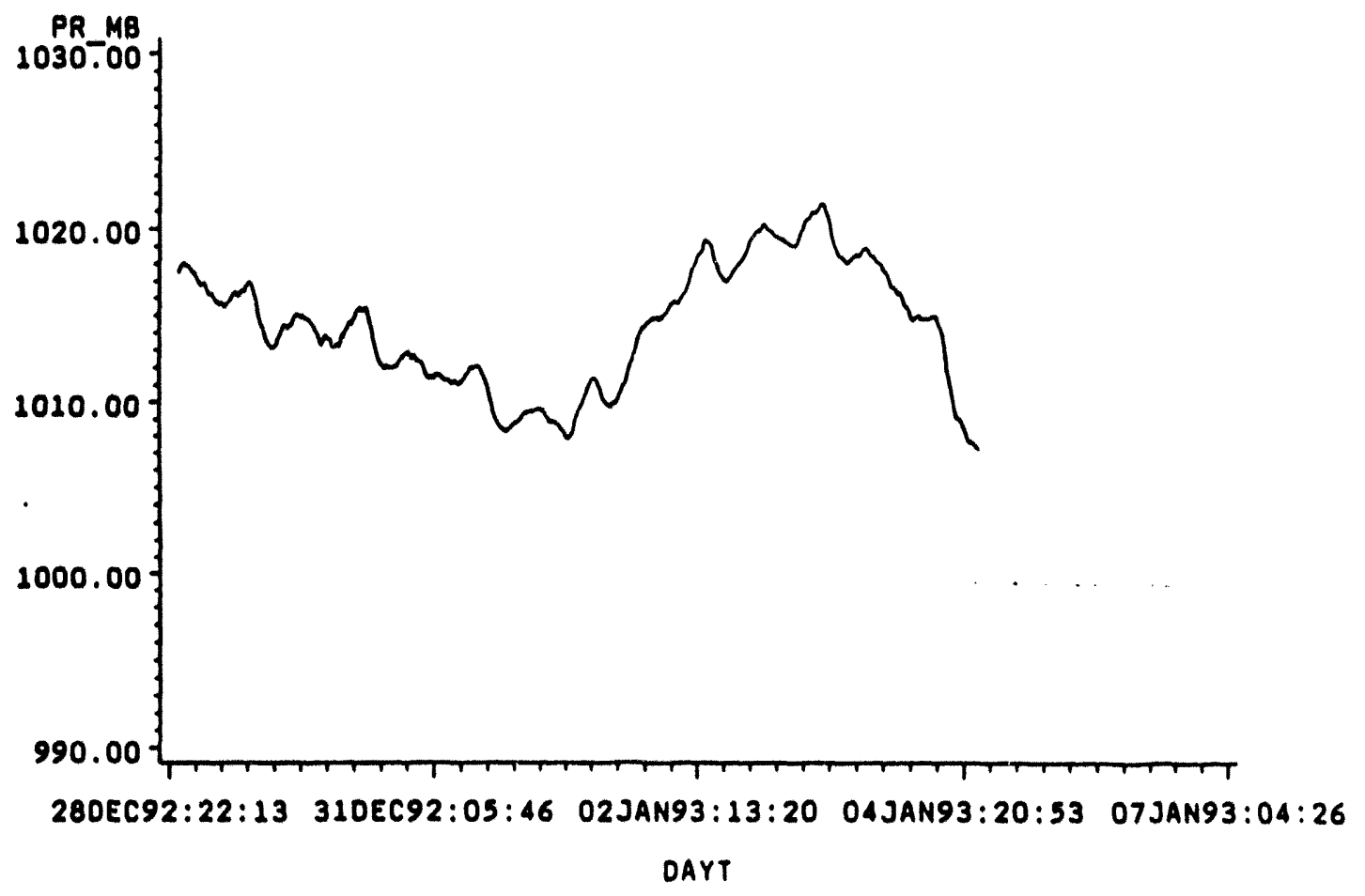

Figure 6. Climatology pressure data for week 5, December 29,1992 January 4, 1993. 


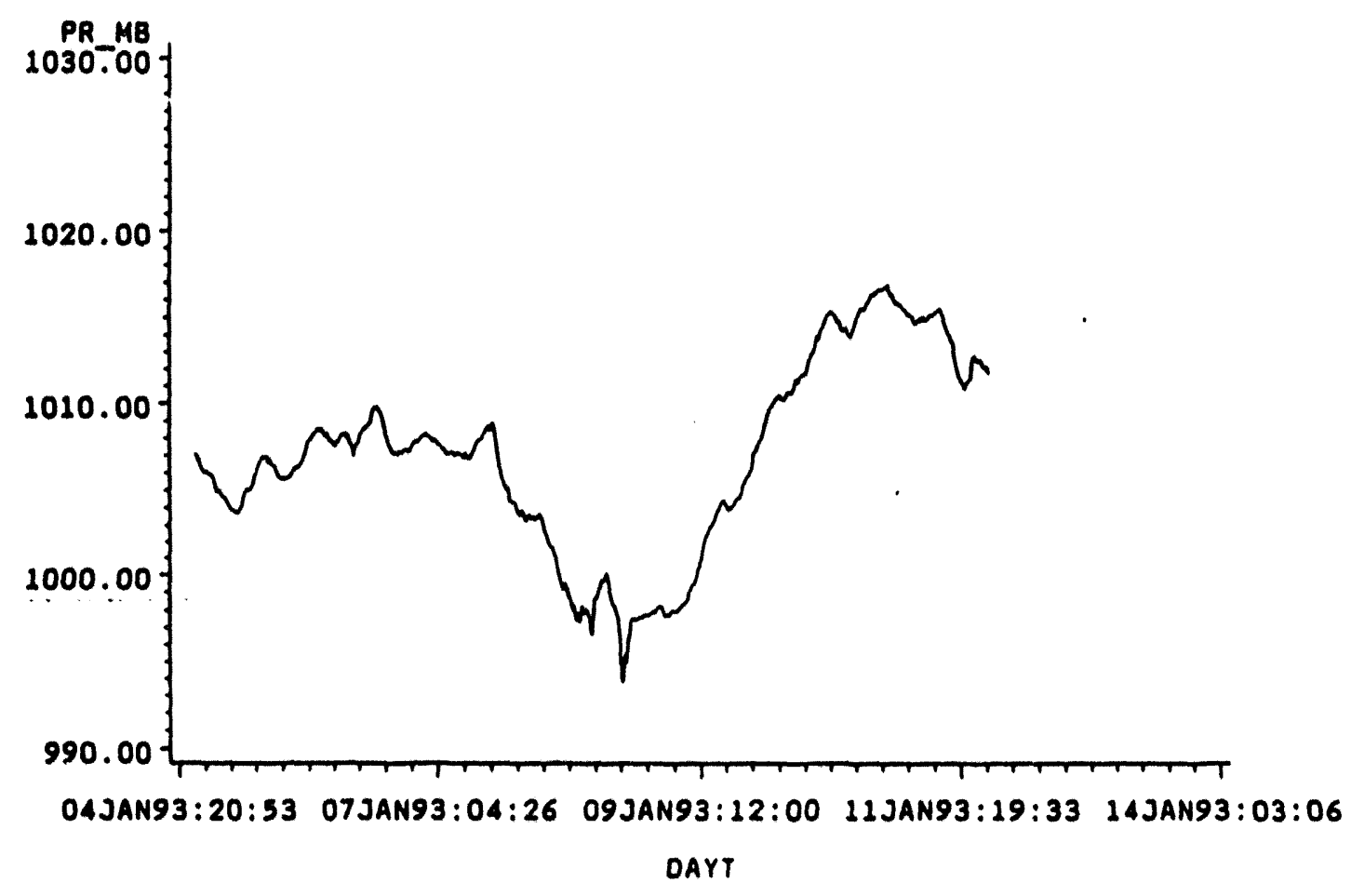

Figure 7. Climatology pressure data for week 6, January 5-11, 1993 


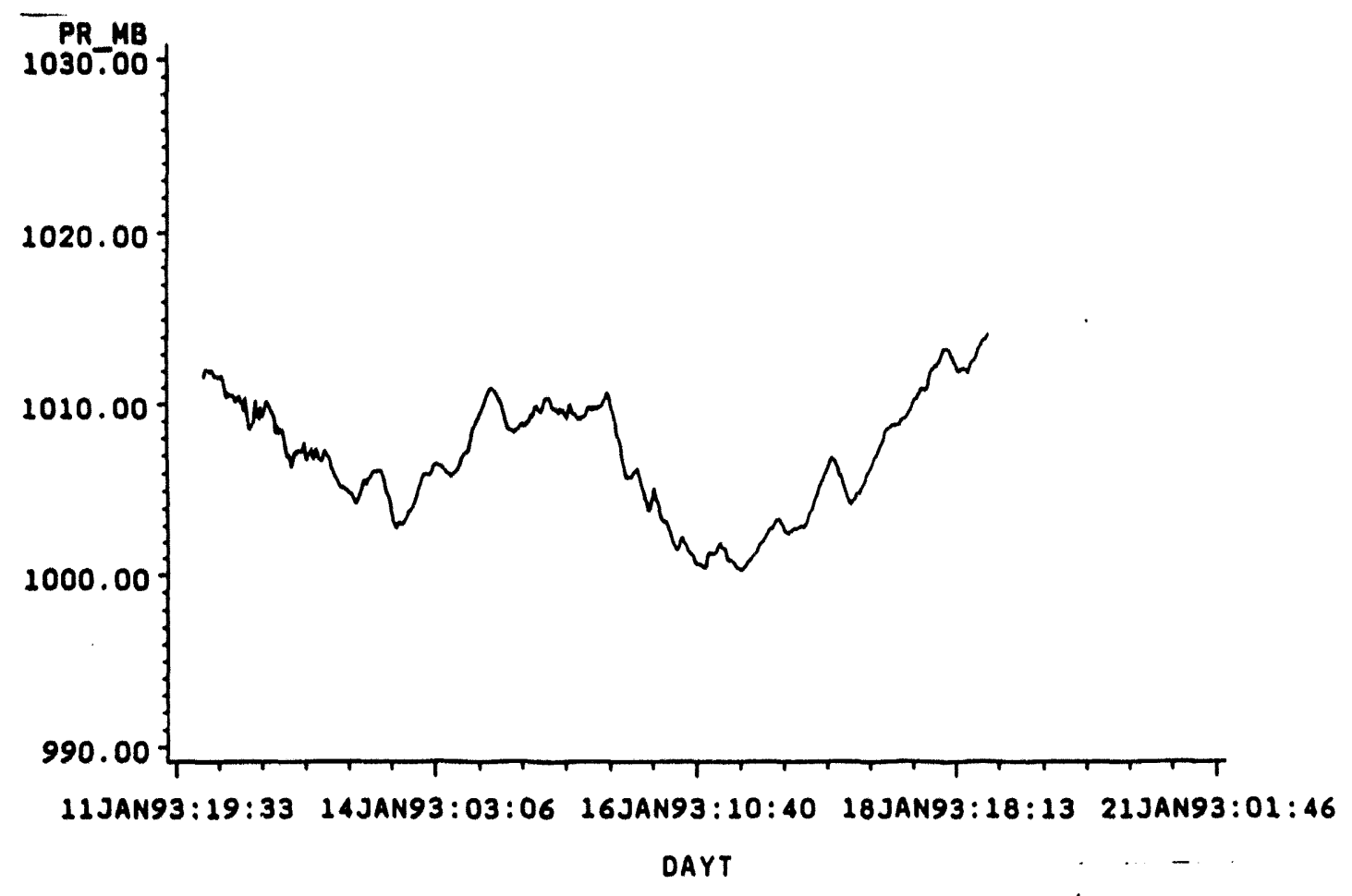

Figure 8. Climatology pressure data for week 7, January 12-18, 1993. 


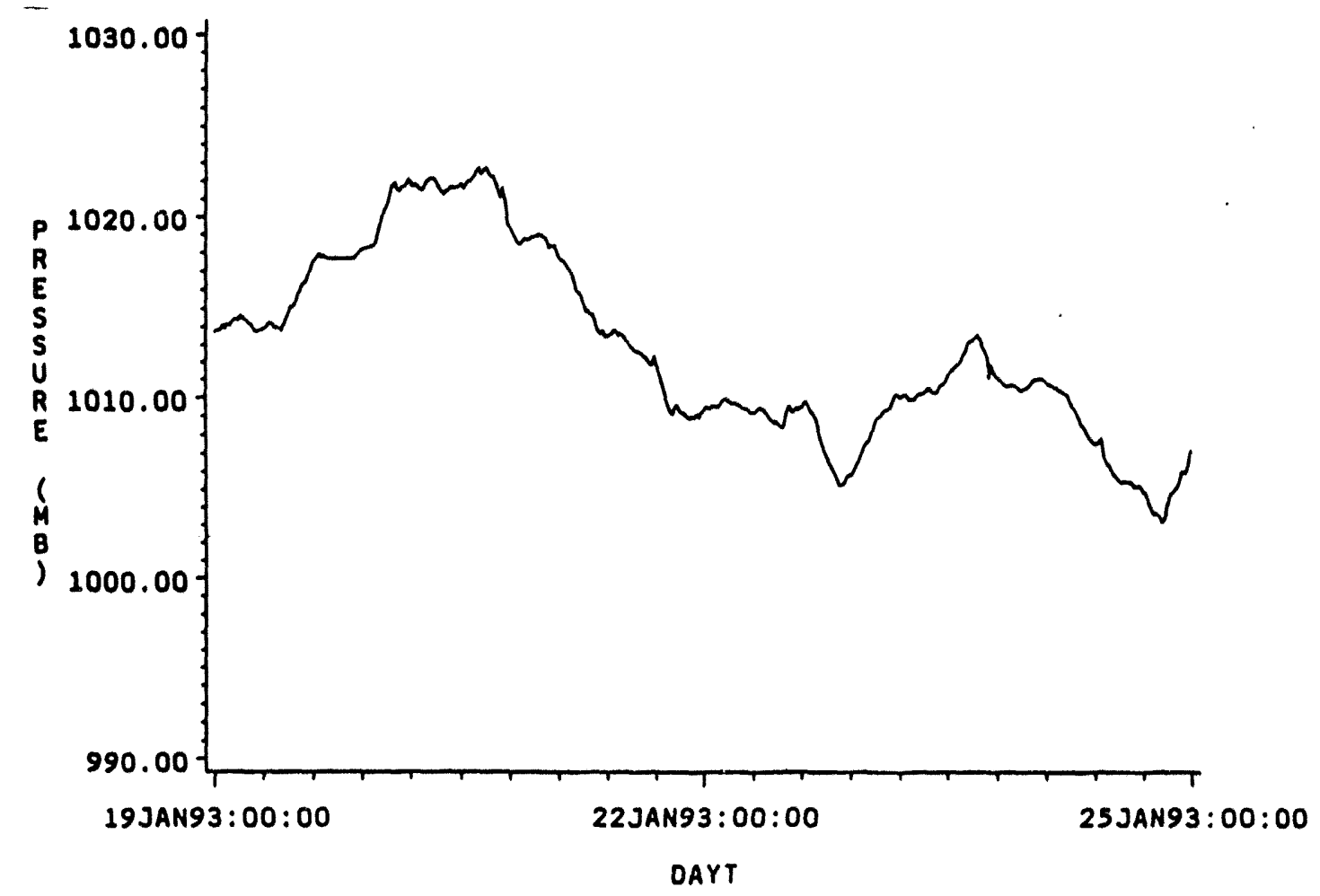

Figure 9. Climatology pressure data for week 8, January 19-25, 1993 


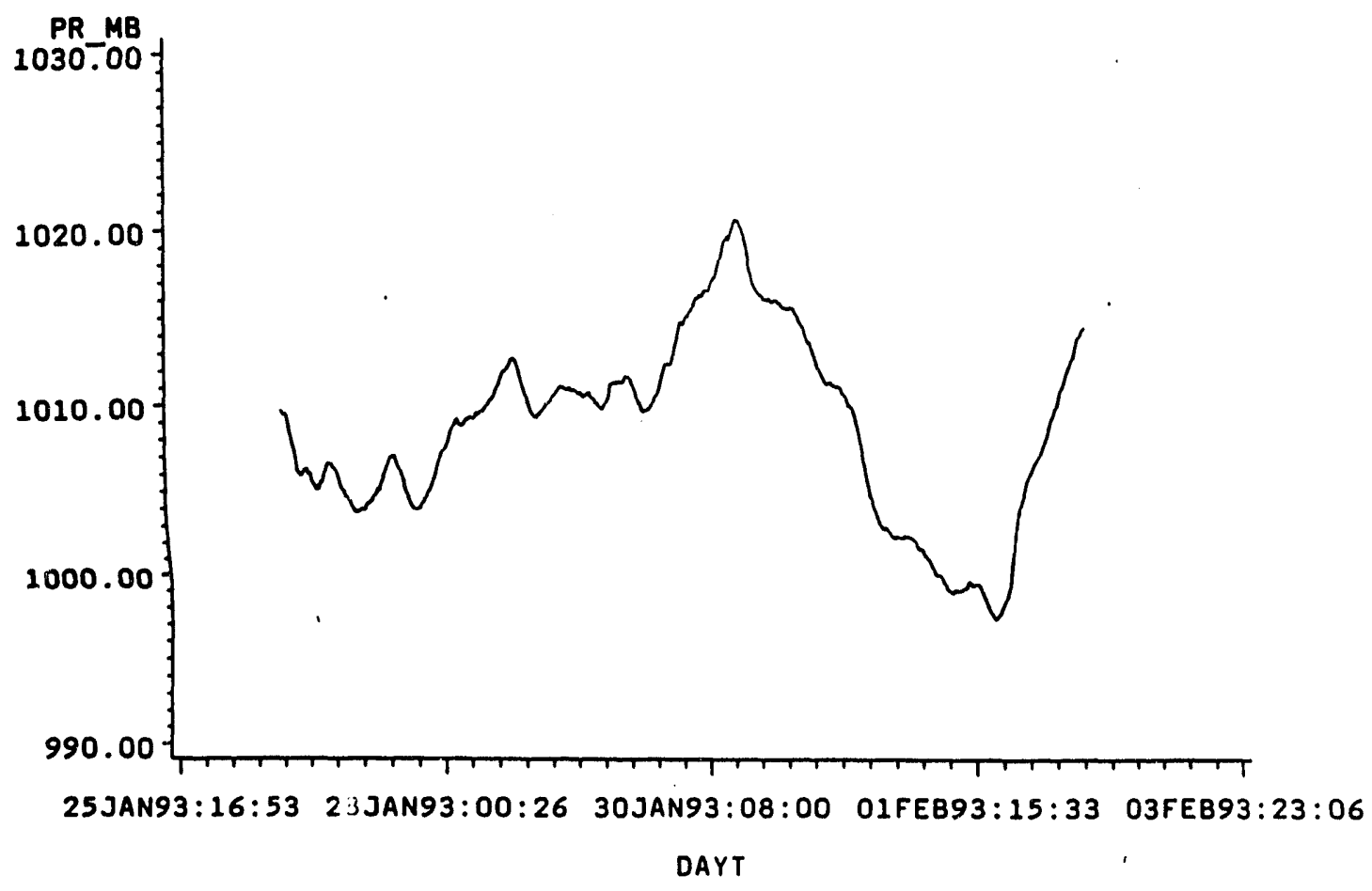

Figure 10. Climatology pressure data for week 9, January 26 - February 2, 1993 


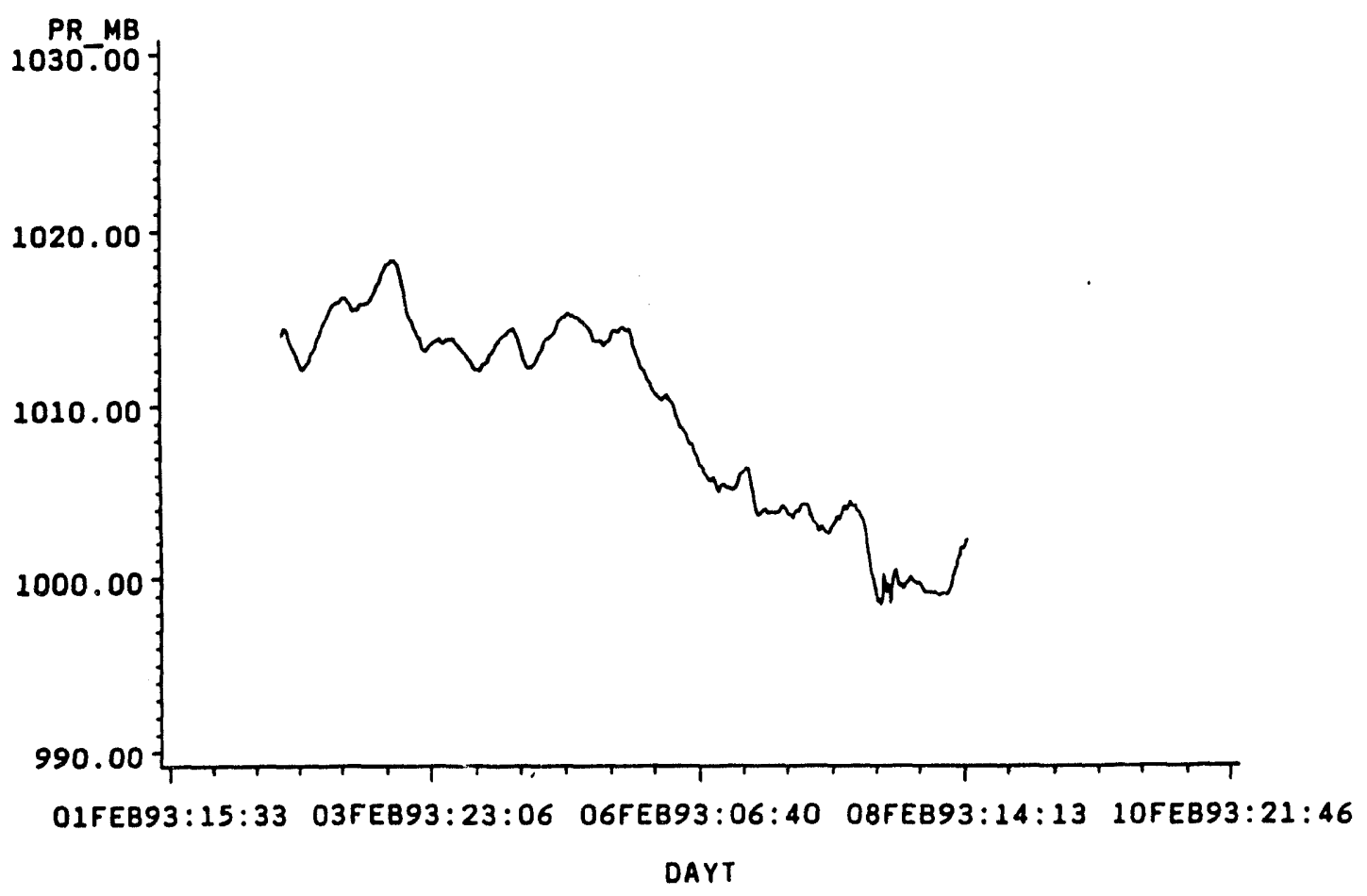

Figure 11. Climatology pressure data for week 10, February 2-8, 1993 

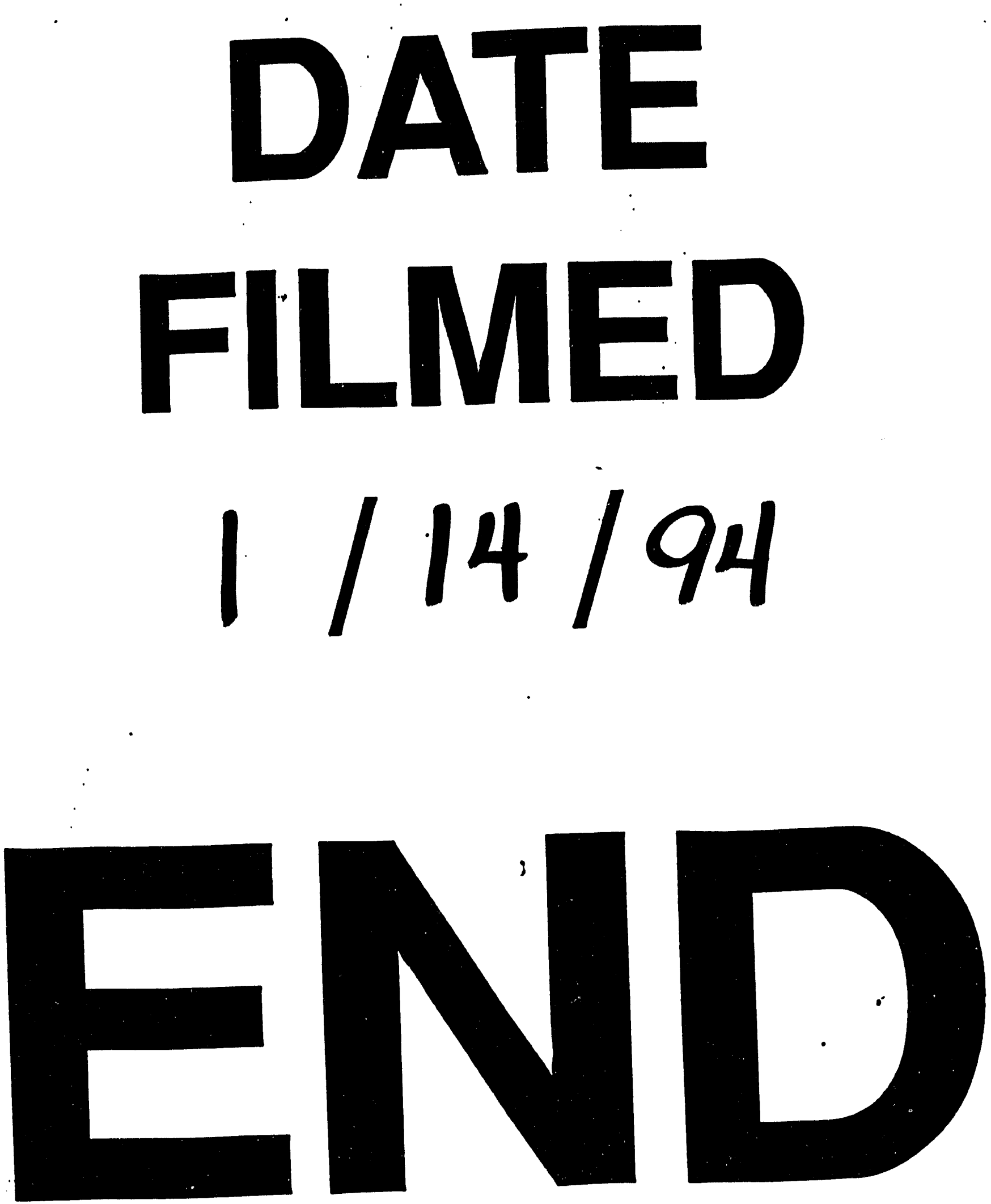